\title{
Effects of breath-hold patterns, gadolinium concentrations and temporal resolutions on determination of mean left atrial circulation transit time by MR first pass perfusion
}

\author{
Jie J Cao ${ }^{1,2^{*}}$, Yi Wang ${ }^{1}$, Michael Passick' ${ }^{1}$ Kathleen Bertman ${ }^{1}$
}

From 17th Annual SCMR Scientific Sessions

New Orleans, LA, USA. 16-19 January 2014

\section{Background}

Normalized mean transit time in left atrium (nLATT) has potential to approximate left ventricular end diastolic pressure (LVEDP). In this study we prospectively evaluated the effects of gadolinium concentrations, breathhold patterns and temporal resolutions on determination of nLATT by MR first pass perfusion.

\section{Methods}

Twenty three patients were prospectively recruited to undergo MRI in a $1.5 \mathrm{~T}$ scanner. First pass perfusion imaging was performed using a saturation recovery steady state free precession sequence with ECG gating during breath-hold with Gadopentetate dimeglumine (Gd) injected at $0.01 \mathrm{mmol} / \mathrm{kg}$. Imaging was repeated with freebreathing followed by breath-hold imaging using Gd at $0.025 \mathrm{mmol} / \mathrm{kg}$ separated with washout periods of 10 to 15 minutes. LATT was determined from the time intensity curves of the first pass using a custom program to assess time-signal integral and normalized by RR duration. nLATT was compared using paired t-test between images acquired in 3 settings. Additional 7 volunteers were recruited to undergo first pass perfusion with dynamic image acquired every 113 ms (TR) without ECG gating. To evaluate the effect of temporal resolution, LATT was assessed using simulated TR sampling dynamic signal intensity at multitudes of TR, respectively.

\section{Results}

Of the 23 patients evaluated average nLATT was $8.60 \pm$ 2.53 cardiac cycles (CC). Using published formula

'St Francis Hospital, Roslyn, New York, USA

Full list of author information is available at the end of the article
$($ LVEDP $=1.78 \mathrm{nLATT}-3.78)$, mean LVEDP was estimated to be $12 \pm 5 \mathrm{mmHg}$ (ranging 5 to $24 \mathrm{mmHg}$ ). nLATT was shorter with free-breathing $(7.57 \pm 2.77 \mathrm{CC})$ resulting in lower LVEDP estimation of $10 \pm 5 \mathrm{mmHg}(\mathrm{p}=0.001)$. In contrast, nLATT was slightly prolonged $(9.34 \pm 3.36 \mathrm{CC})$ with higher Gd dosing resulting in modestly increased LVEDP estimation of $13 \pm 6 \mathrm{mmHg}(\mathrm{p}=0.106)$. In 7 patients tested with simulated TRs there was no significant change in LATT of $7.03 \pm 1.6 \mathrm{~s} 7.02 \pm 1.7 \mathrm{~s}, 7.38 \pm$ $1.5 \mathrm{~s}, 7.07 \pm 1.5 \mathrm{~s}, 7.66 \pm 1.4 \mathrm{~s}$ and $7.59 \pm 1.7 \mathrm{~s}$ corresponding to simulated TRs at $113 \mathrm{~ms}, 226 \mathrm{~ms}, 452 \mathrm{~ms}, 678 \mathrm{~ms}$, $791 \mathrm{~ms}$ and $904 \mathrm{~ms}$, respectively ( $\mathrm{p}$ for trend $=0.406$ ).

\section{Conclusions}

While nLATT assessment using free-breathing acquisition may result in lower LVEDP estimation than breath-hold technique, albeit small absolute difference, the effects of Gd concentration (up to $0.025 \mathrm{mmol} / \mathrm{kg}$ ) and temporal resolutions on nLATT assessment are limited.

\section{Funding}

St Francis Research Fundation.

\section{Authors' details}

${ }^{1}$ St Francis Hospital, Roslyn, New York, USA. ${ }^{2}$ Cardiology, State University of New York at Stony Brook, Stony Brook, New York, USA.

Published: 16 January 2014

doi:10.1186/1532-429X-16-S1-P234

Cite this article as: Cao et al:: Effects of breath-hold patterns,

gadolinium concentrations and temporal resolutions on determination

of mean left atrial circulation transit time by MR first pass perfusion.

Journal of Cardiovascular Magnetic Resonance 2014 16(Suppl 1):P234. 